\section{That Fantastic Century}

Tom Shippey:

J.R.R. Tolkien: Author of the Century

(Boston: Houghton Mifflin, 2001)

The review is a particularly ominous genre for Tolkien Studies; apparently it has always been its nemesis. The dismissive early reviews of The Lord of the Rings (henceforward: $L R$, published in 1954-55) seem to determine Tolkien criticism to some extent to this day, giving it a decidedly apologetic tone. Generally, Tolkien's reception is still, sixty-five years after the publication of The Hobbit (henceforward: $H$ ) in 1937, rather cold and measured (if that), and the reputation of his texts still mirrors the extremes of the first reviews: enthusiasm or contempt. The popular Tolkien 'cult' has usually not moved academics to appreciation, and although there are certain cracks that might be observed in the canon today, Tolkien has by no means penetrated the critical canon or the publishing space of 'high academia.' The 'Tolkien phenomenon,' nevertheless, remains a peculiar and interesting one; but writing about it in a review certainly has its ironies.

The Tolkien cult and Tolkien criticism developed in originally separate but later frequently intersecting ways, producing a schizophrenic situation in the possible relations to Tolkien. The cult and eventually the phenomenon started as early as the publication of $L R$, and has continued unabated since then, now again strengthened by Peter Jackson's film adaptation. Fan clubs and Tolkien Societies sprang up on both sides of the Atlantic, publishing many newsletter-type fanzines and periodicals (which eventually grew into [near] respectable journals: e.g. Mythlore, the periodical of the US-based Mythopoeic Society, or Mallorn, that of the British Tolkien Society) in which much critical writing is printed. Fans had their part in initiating the writing of Tolkien criticism; academic commentary first tried to position itself in opposition to fans and to disparaging reviews. C.S. Lewis and W.H. Auden were two professional critics who (besides writing appreciative reviews) fostered this other side of the approach to Tolkien. The interaction of the two kinds of criticism has become much more complex and cooperative by now, and much 'fan criticism' has definitely been absorbed in 'academic criticism.' Yet Tolkien 'fandom' is alive, and the tensions between it and criticism are still to be observed in their reactions to each other and to the prolifera- 
tion of their material in recent years.

For the Tolkien corpus has been considerably expanded in the posthumous publications, and the importance of this cannot be underestimated. More Tolkien texts appeared in the last twenty-five years than he had ever published in his life: his youngest son and literary executor Christopher edited fourteen volumes of material between 1977 and 1996 (The Silmarillion [1977; henceforward: Sil], Unfinished Tales [1980], and the twelve volumes of The History of Middle-earth [1984-96; henceforward: $H M E]$ ). Sil, a continuous text, gave historical and mythological depth both to $L R$ and $H$; it is in fact an editorial text made up of several distinct manuscript versions. But $H M E$ made evident that most of the material is essentially unlike the 'finished texts' ( $H$ and $L R$ ); the whole nature of the corpus has radically changed. These are writings unlikely to be appreciated, showing the development of Tolkien's work (hence the series title) in the variants of stories, never finished but (despite that) always reworked and rewritten, related in some problematically definable way both to each other and to the 'finished texts.' Their significance is great; yet criticism is slow to turn towards them, and even interpretations of Sil are very rare still.

However, serious and scholarly Tolkien criticism runs up against the silence of the 'theoretical side.' No one seems to respond to this work from inside the poststructuralist critical context; strangely enough, since Tolkien's texts offer much that could interest the theorist and the poststructuralist critic. The essential plurality of the expanded corpus, its peculiar conception of textuality and story, fit in very well with directions of the New Philology and some narratological considerations, while the parallels in (and allusions to) manuscript culture and orality enable a wider Cultural Studies perspective. The suggestion of meaning as 'fluctuating' between versions, always under revision, should be attractive for most theories of interpretation. But approaches now cannot fasten on any one text any more ( $H$ or $L R$, or even Sil) - they should take in the whole in its plurality. Tolkien's work is a radical cultural (not only literary) fiction, demanding thought and response. That it is, despite all this, not acknowledged as the object of 'legitimate' study, is symptomatic of something; something that could be detected in the earliest disparaging reviews. Tom Shippey's J.R.R. Tol- 
kien: Author of the Century ${ }^{1}$ sets itself the task of finding out what it is.

Perhaps no scholar has done more for the understanding of Tolkien than Tom Shippey. His first book on Tolkien, The Road to Middle-earth ${ }^{2}$ has been called "the single best thing ever written on [the topic]." Its importance lies in its methodological coherence, and its historical perspective: it was the first to systematise and set out in meticulous philological detail how Tolkien's relation to his sources determined his texts. Shippey's exposition and virtuoso use of the method of philological reconstruction showed how the integration, adaptation, and imaginative reworking of ancient literature worked. His discussion of the adapted generic, characterisational, and narrative conventions and authorial techniques was underpinned by a sensitive detection of the many conceptual patterns and elements Tolkien also subtly built in (like the Christian and Germanic pagan concepts in $H$ and $L R$ ). In Road Shippey collected pieces of philological detail (obscure words, stories, unexplained references in medieval texts) which Tolkien started with, and showed how the linguistic, narrative, and mythological context was built up around them. He also examined how the insertion of characteristic (and dar- ing) anachronisms (like the hobbits) served to mediate this world successfully. In this historical perspective, Road was also the first to answer, comprehensively, validly and wittily, Tolkien's early and later detractors. It is a massively useful 'resource cum interpretation,' written with elegance and formidable erudition.

While Road served to "set Tolkien's work in a philological context" (xxvii), the scope of Author is more contemporary but necessarily wider and less specific: to supply the synchronic complement to Road's diachronism. "While I remain convinced," Shippey writes, "that Tolkien cannot be properly discussed without some considerable awareness of the [philological context], [... ] I now accept that he needs also to be looked at and interpreted within his own time, as an 'author of the century"' (xxvii). And Tolkien is perfectly in place in that century, itself peculiar: 'the fantastic' has apparently been its "dominant literary mode" (vii). Comparisons with canonically undeniably influential authors and texts (e.g. with James Joyce, see 31012 , 261; vii-viii, generally 305-28) back up the point. The 'fantastic,' Shippey hints, is defined as in opposition to modernist and realist conventions (viii), deliberately contradicting or even ignoring the way 
twentieth-century readers and critics routinely read and take for granted. Author builds on the argument of Road, continuing it to different conclusions, situating Tolkien's anachronism inside a contemporary context, and seeks to understand it in this relation.

The difference is primarily in method and approach. The account of philology and the idea of historical and comparative reconstruction (the first fifty pages of Road) are summarised in five pages (xii-xvii), with definition, method, and history. Shippey begins in medias res, with the texts, not only illustrating but making the methodological point in their discussion. This surely results -from the difference in outlook. Road, heavy with detail, historical linguistics and comparative mythology, was rather an 'academic monograph' with notes, appendices, written in a more specialised and scholarly style. But in (/with) Author Shippey concedes that "not everyone takes to Gothic, or even (in extreme cases) to Old Norse" (xxvii). This book is clearly aimed at a more general readership: there are no notes, few references (though there is a useful bibliography), a less painstaking exposition of philological evidence and source material. It is written in an elegant, lucid but unmistakably more accessible style than was Road. It has been said that Road attempted to expound a basically medievalist approach to Tolkien to those who are not medievalists; Author, then, explains a more generally critical approach to those not critics.

Consequently Author is built up around chapters on the more accessible Tolkien texts; and this is necessarily a smaller corpus than Road's. The centre is occupied by $L R$ (three chapters), with $H$ and Sil (one chapter each) running up; some minor works (where Shippey maintains his view of the 'autobiographical allegories,' contested since Road by Verlyn Flieger and David Doughan ${ }^{4}$ ) and problems of the critical context are also discussed. The focus is on the 'fixed texts,' in a way seeing much of Tolkien's work in relation to $L R$. This is, considering the general reading chronology, the thing to do - but the $H M E$ corpus, for example, is not always readily meaningful in that relation, and the implications of these texts is a point which is merely touched upon. But a broader audience means focus on the texts that this audience reads, and a loss of the implications of the texts it does not.

Chapters 1-2 treat the creation and structure of Tolkien's Middle-earth through $H$ and $L R$. The emphasis falls on the role of language, in all its 
levels, historical forms and stylistic registers, in the creation of the 'fantasy world.' The result is a "complex map [...] of cultures, races, languages, and histories" (102). It is a 'philological fiction,' based on ancient English and Norse literary sources, produced by a consistent use of the philological reconstructive method. Tolkien "took fragments of ancient literature, expanded on their intensely suggestive hints of further meaning, and made them into a coherent and consistent narrative" (35). Various devices and techniques are used to mediate this deeply traditional world (anachronistic mediator figures, the hobbits, integrated ingeniously into the context; the handling of the authorial voice in narrative and comment; the anchoring effect of names; historically and linguistically different styles and rhetoric in creating and maintaining character, etc.), leading to a "sense of variety and verisimilitude" (65). The cultural parallels and contrasts, and the use of the narrative technique of interlacement (107) give this world further "inner consistency" (84). One particularly important quality which Tolkien's texts share with their sources, and which Shippey determinedly stresses all through is the suggestion of historical and narrative depth; another is the underlying idea of the continuity of traditions which make the traditional world 'mediateable' at all.

How this world actually works to produce meaning in $L R$ is the subject of Chapters 3-4. What makes it relevant, Shippey argues, is the characteristically twentieth-century problems it presents, most of all that of the connection of evil and power. Tolkien's powerful and psychologically plausible images of the wraiths and orcs comment on this effectively, complemented by the adaptation of two traditional conceptions of evil (in Shippey's terms, Boethian and Manichean, evil as absence or substantial presence), the oscillation between which is emblematised in the ambiguities of the Ring. Tolkien's reactions to evil include adapting another traditional stance, the "Northern theory of courage" (149). It is this profound 'traditionalism,' Shippey now suggests, that causes critical hostility: critics simply find this irremediably outdated and irrelevant $(156,158-60)$. Yet Tolkien transcends both the nostalgically traditional and the allegorically contemporary: Chapter 4's examination of the 'mythic dimension,' both in particular cases and in general, argues for a 'mythical' interpretation. Myths as stories, texts or symbols are "always available for individuals to make over, and apply to their own 
circumstances, without ever gaining control or permanent single-meaning possession" (192); the connection with Tolkien's made-over traditions is obvious. But in its mediator function too, myth has a parallel in $L R$, itself mediating both between the Christian and the pre-Christian and the Christian and post-Christian worlds (213). The very concept of depth, perspective, and detail used as a 'reservoir' of meaning to draw upon and apply reflect the similar traits and functions of mythology.

Why depth is emphasised all through is explained in Chapter 5, about Sil. Sil is essentially different from the previously discussed 'fixed texts' (which are in effect its "offshoots," 226) in its having become a "fixed tradition" (228) in the complicated writing chronology of Tolkien's work. His reconstructive creation of world and story was at its most ambitious aimed at producing a 'mythology for England," stories which could 'fill in' for the lost mythological material of Old English (and by descent, English) culture. In the process not only historical/ narrative depth was created ('a suggestion of more stories'), but an impression of age, sources, authors and compilers. Depth in Sil is not merely a quality of a shady background, it is the effect of tradition; for Tolkien, this role is played by 'the' traditions of the elves and is mediated by them (242). But their story is again produced by reconstructive starting points and expansion, structured along cultural, familial, and linguistic divisions, so that its organisation "makes demands upon its readers which no other modern work has ventured" (246). These structures and themes are always mirrored in language (Tolkien's famously elaborated elvish languages), and in another sort of mediation, the relationship between elvish and human cultures, found in the "human-stories," which concern elvish tradition and central concepts (death and immortality, fate, evil again, only from the elvish viewpoint).

Myth and Christianity are also inserted by way of reconstruction: the central story of intercession and forgiveness, with elements from both traditions, the "complexes of meaning [apparent in this fusion] suggest that history, and linguistic change, keep on generating new meanings from words and demanding new versions of story" (260). The mere fact that "myths always need retelling" (261) could explain the proliferation of versions; and while the form of Sil as a 'compendious' corpus conceived of as a text is a reflection on tradition and its transmission, it also reflects on authority and textuality. Sil is thus seen in its 
problematic textual status, as a more 'plural' and 'mobile' text; itself a corpus of texts.

Finally, Shippey also touches upon the generic question in Tolkien's texts. In a Fryean typology, he says, $L R$ is "a romance, but one which is in continuous negotiation with and which follows many of the conventions of the traditional bourgeois novel" (223). Sil, on the other hand, "stays resolutely on the level of "high mimesis' or above" (256), which makes it difficult to read and to appreciate. The clash of two or more of narrative and stylistic traditions thus effectively explains some of the academics' bafflement, and also why $L R$ is thought to be 'more central': it is more accessible.

The Afterword deals with questions of criticism, and appropriately returns to the question of Tolkien's noncanonicity and his general dismissal by literary critics. One of the conclusions is perhaps that 'fantastic' is not an entirely convenient term for Tolkien's work, and 'traditional(ist)' would probably serve better; unless we are ready to label the greater part of literary history 'fantastic.' Technically, 'fantastic' has not been defined - only signalled by references to authors and texts supposedly in this category. The politics of criticism is clearly problematised here: not only is criticism hostile to Tolkien, but it is also strongly marked by its ignorance of what it criticises, or only a very superficial knowledge, applied in tendentious and wilfully imperceptive ways. Shippey here, as in Road, elegantly refutes such positions. $\mathrm{He}$ shows (here employing the comparison with James Joyce) that the 'modernist' principles of writing and criticism will not cover Tolkien because his work presents tradition as "on principle not literary" (315), not 'high' or 'low' but pervading culture and present in the 'lowest' of its strata and stories. This is a highly professional approach, but "populist, not élitist," threatening "the authority of the arbiters of taste" (316), traditional over the head of those who think to be controlling tradition and the forms it can be presented in. Dismissive and hostile criticism shows all the rhetorical traits of attempted marginalisation, and Tolkien is often dismissed even from discussions of the 'fantastic.' The 'fantastic,' then, seems to be just a (post-) modernist construction (going back to Todorov), positioned as vs. 'realistic (and/or ironic), yielding a term of rather limited literary historical applicability.

Shippey's comparison with Joyce also points out the paradox that in other instances exactly this lack of 
realistic convention is lauded loudly. There is nothing in Tolkien's writing or concept that would inherently exclude him from the canon; but it is no wonder that texts with which critics refuse to engage in the first place will not be canonical. Shippey finds the cause of this refusal (in a way, this is another conclusion of the book) in the 'ideological gap' between modernist principles and Tolkien's popular appeal - and indeed he cannot do anything else, since hostile criticism produced only superficial arguments against him. Looking further, though, one can see various other 'excluding factors' levelled against Tolkien, all of them heavily ideological: he has been called fascistic, sexist, racist, escapist, and other names which are blatantly untrue ${ }^{6}$ the problem is, I think, merely Tolkien's traditionalism, which the critics sense as an incurable anachronism. In Barthesian terms, Tolkien attempted to write the 'unwritable,' the 'readerly,' the 'classic' (even with success, as it turned out, and quite meaningfully and relevantly, as Shippey shows); this is supposed to be a 'theoretical impossibility,' and since critics of modern /postmodern/contemporary literature are simply not equipped to deal with such texts (their conceptual framework, historical dimensions, stylistic subtleties) and cannot grasp the nature and importance of the relationship to the medieval parallels, they choose to exclude it rather than bother to modify their theoretical frameworks. The earlier modernist adversaries did this by reference to the taste of the "literati" (thereby excluding him from the canonical 'high culture'), while postmodernists now do the same by reference to any particular ideologies the poststructuralist framework might focus on (thereby excluding him from the theoretically/ideologically determined canonical 'contemporary'). But while refusing to acknowledge Tolkien's work, criticism is refusing to see the cultural phenomenon of 'fantasy literature,' none of which, Shippey says, "has managed to escape the mark of Tolkien" (326), and where he has become a sort of 'substratum' of a literary culture. When ignoring to engage with literature that is really read, this kind of criticism also ignores that the distinction between 'high' and 'low' cultural forms has generally broken down, and that tradition can legitimately be utilised in other ways than those favoured by critics in any given historical period. A.J. Minnis's words ring true: "[1]iterature is not firmly controlled by the literary theory contemporaneous with it (to think 
otherwise is, in my view, to be naive about the nature of literary theory)."

Shippey closes Author by remarking that there is nothing inherently more direct, more immediate in the representations within realistic conventions - Adam Bede is just as much a fiction as $L R$. The 'fantastic' by implication is defined not as a way of writing but as a 'cultural discourse,' by the radicalness of its insistence on fictionality, opposed to realist and modernist principles and conventions of interpretation. It implies a specific mode of reading and another kind of critical relationship. $L R$ can perhaps be read as a modern 'novel' (though Shippey warns of the dangers of reading it entirely as one), but Sil and HME (the greater part of the Tolkien corpus) certainly cannot: their conception, narrative techniques, characters and themes, and most of all, language and style, simply will not stand if read within a novelistic framework. Yet they undoubtedly succeed to produce meaning, and not only in the fans (the argumentum ad populum is always suspicious, as is the automatic contempt for the fans) complex and entirely legitimate structures of meaning can, as Shippey shows, be detected in them by exactly the same critical methods that work on other, canonical text. The irony in this is that after all Shippey too is dragged into the politics of criticism, suggesting (as he did at the beginning) that Tolkien's most appropriate critic is the medievalist. Theorists (literary, cultural, and otherwise) usually do not care to read the literary historical background; and the whole of Author is proof that it is essential. Tolkien's traditionalism, then, is projected back onto the critical plane: he introduced "a new, or possibly re-introduce[d] an old and forgotten taste into the literary world" (328). His work now highlights the possible use of an old and near-forgotten method, philology, for criticism.

Though Shippey only goes this far in a book aimed at a general audience, his argument holds much for more specialised Tolkien Studies to go on with. Surely Tolkien's traditionalism is not merely a 'modernistbashing' device - it has its own conception of literature, understanding it as a focus of language, culture, and narrative, all of them historically conceived, pinned down to and determined by ancestry and history instead of 'floating in a flux.' One consequence is the enormous theoretical significance of textuality in Tolkien, and this points out what is missing from Author: a discussion of HME. Road, and more recently an 
essay collection Tolkien's Legendarium ${ }^{9}$ treated it - but the lack of a discussion of the essential variation and fragmentedness of most of the Tolkien corpus (thirteen volumes eventually leading up to Sil, an editorial construct as a 'fixed text') is definitely felt here. It implies a division of the corpus to the 'popular canon' of 'fixed texts,' and a 'critical' one of entirely different nature.

$H$ and $L R$ are 'offshoots'; Sil is a cross-section; HME, being the 'tradition,' enables critical appreciation of further foci of the 'philological theory of literature' - what we have to realise is that Tolkien's work is the whole corpus, including all texts. The 'fixed texts' rely on the variants as ancient texts on ancient culture; not only (a particular) culture is suggested, but whole frameworks, contexts. Not separate and distinct cultures are examined (in relation to each other, as in $L R$ ) but culture itself, in its relation to its expressions (such as orality or textuality), functions (such as transmission of traditions or identity production), and history. Tolkien's uses of texts can be seen in this light: the text as never fixed, always rewritten and revised parallels the revision and adaptation of story, and thus reflects on the mythological dimension (cf. 261). Language in this is seen as the 'glue' of culture: the inevitable lens through which we see the world, ourselves; the medium producing its own realities in stories; and our only way to make sense of these. As in mythology (with which Tolkien is frequently associated), the telling of the story keeps tradition alive; the use of the story gives it its peculiar status. Tolkien's work 'models' tradition in a unique way which is very much relevant and legitimate today.

Tolkien can also be effectively claimed for postmodernism (such an attempt has been made by Patrick Curry ${ }^{19}$, and Author sometimes hintingly suggests lines of interpretation which fit in well with poststructuralist and postmodernist perspectives. The way the linking of knowledge with ideology and power is presented, the role of authority as a controller of discourse and thus of knowledge (a decidedly Foucaultian theme), the all-pervasive role of textuality in culture and the problematics of authority and the transmission of authority in text and history are unquestionably of interest to current schools of critical thinking. The imaginative depiction of the 'Fallen World of Men' could be seen as a world where language is not stable and does not provide anchors to 'truth.' Tolkien, however, handles these problems on the theological 
level, not a general theoretical one; but then theology itself is integrated into the network of cultural interactions, discourses, and frameworks of thought. What Author does is entirely justified and valid: complementing Road's diachronic approach, it opens up the synchronic dimension in a widely accessible way, and yet is pregnant with new critical perspectives, pointing to directions for further work.

Tolkien Studies is in some sense, after nearly fifty years, a relatively young field of study. The 'phenomenon' continues, but is not only a 'popular' one any more; at any rate it cannot be contemptfully dismissed as such. It has become evident too that Tolkien does not need an apology; nor do Tolkien fans, or academics finding interest in his writings. But work on the sources is largely done; other 'traditional Tolkienist topics' (like the Good-and-Evil question) are tired and exhausted; ${ }^{11}$ new approaches are needed. Tolkien Studies, as one critic recently put it, seems to have come of age, and goes towards more contemporary directions, opening up more theoretical fields, to explore the connections between the traditional and the theoretical in textual and cultural space. But Tom Shippey's books will remain benchmarks, and stay with us to remind critics of the importance of the conception and method of philology. GERGELY NAGY

\section{NOTES}

1 Henceforward: Author. Unqualified page references in my text will be to this book. I am most grateful to Professor Shippey for having sent me a copy.

2 T.A. Shippey, The Road to Middle-earth (London: Grafton, 1982; rev. ed. 1992), henceforward: Road.

3 Michael D.C. Drout and Hilary Wynne, "Tom Shippey's J. R. R. Tolkien: A uthor of the Century and a Look Back at Tolkien Criticism since 1982," Envoi 9.2 (Fall 2000) 101-165, p. 101.

4 See Author, p. 297. David Doughan, "In Search of the Bounce: Tolkien Seen through Smith," Leaves from the Tree: J. R. R. Tolkien's Shorter Fiction (London: Tolkien Society, 1991), 17-22 (I also owe thanks to Professor Shippey for sending me a copy of this rather rare publication); Verlyn Flieger, $A$ Question of Time: J. R. R. Tolkien's Road to Faerie (Ohio: Kent State University Press, 1997). 5 Tolkien's best-known formulation of this is found in his long letter to Milton Waldman (1951), found in Humphrey Carpenter, ed., The Letters of J. R. R. Tolkien, (Boston: Houghton Mifflin, 1981), pp. 143-161 (my thanks are due to Verlyn Flieger for making this volume available to me). A portion of this letter in now customarily printed in the new editions of Sil. See also Drout and Wynne, pp. 111-13. 6 See Patrick Curry, "Tolkien and His Critics: A Critique," Root and Branch: Approaches to. wards Understanding Tolkien, ed. Thomas Honegger (Zurich and Berne: Walking Tree Publications, 1999), 81-148. I think Curry overpoliticises Tolkien (if not the critical reaction to him), which perhaps detracts from the value of 
his defence. (I am grateful to Professor Shippey, who sent me a copy of this book.)

7 C.S. Lewis and W.H. Auden obviously did not count as 'literati' for such reviewers, an irony in itself.

8 A.J. Minnis, Medieval Theory of Authorship: Scholastic Literary Attitudes in the Late Middle Ages (Aldershot: Wildwood, 1988), p. xvii.
9 Verlyn Flieger and Carl F. Hostetter, eds., Tolkien's Legendarium: Essays on The History of Middle-earth, (Westport, Conn. and London: Greenwood Press, 2000). 10 Patrick Curry, Defending Middle-earth: Tol. kien: Myth and Modernity (London: Harper Collins, 1997); Shippey, p. 309.

11 Drout and Wynne, pp. 106-11. 